Original Article

\title{
Rhomboid fossa and mid shaft circumference of the clavicle - anthropological study in North Karnataka population
}

\author{
Shivarama Bhat ${ }^{1}$, M uhammad Asif', Dinesh Sosalagere Manjegowda ${ }^{3}$, \\ Shetty Radhakrishna ${ }^{4} \&$ Shivarama C.H. ${ }^{5}$
}

${ }^{1}$ Professor, ${ }^{2}$ Lecturer, Yenepoya M edical College, ${ }^{3}$ Assistant professor, Nitte University Centre for Science Education \& Research (NUCSER), K.S. Hegde Medical Academy, ${ }^{4}$ Associate Professor, ${ }^{5}$ Assistant professor, Kanachur Medical College, Mangalore, Karnataka, India.

\author{
Correspondence \\ Shivarama Bhat \\ Professor, Department of Anatomy, Yenepoya Medical College, M angalore - 575 018, Karnataka, India. \\ M obile : +919448811296 E-mail : bhatshivarama@gmail.com
}

\begin{abstract}
The rhomboid fossa of clavicle was studied globally by forensic experts and anthropologiststo determine the age and sex. This study was done on samples of human clavicles from North Karnataka of South India to determine the sexual dimorphism which is of anthropological, forensic and clinical importance. In this study mid shaft circumference, morphology of rhomboid fossa of clavicle was analysed. The incidences of rhomboid fossa of depressed and elevated types are seen more in males and smooth and flat types are seen mainly in female clavicles. This study also showed relative degree of sexual dimorphism in the mid shaft circumference of male and female clavicles. Since morphology of rhomboid fossa and mid shaft circumference of clavicles are significantly associated with sex, these results can be correlated with further molecular studies. These results may be used as indicators to determine sex in anthropology and forensic science to aid identification of isolated bone specimens.
\end{abstract}

Keywords: forensic science, rhomboid fossa, morphology of clavicle, anthropology, sexual dimorphism.

\section{Introduction}

The clavicle is described as a long bone which has a shaft and two ends. ${ }^{1}$ The costoclavicular ligament (ligamentum costoclaviculare) or rhomboid ligament, on its insertion in the inferior surface of medial end of clavicle, can produce impressions, tuberosities, depressions, and even a fossa, known anatomically as the rhomboid fossa, ${ }_{1}^{11}$ which is of anthropological importance. Sometimes the depressed type of fossa may be very large and is called as excavated in type morphologically.

In the identification of humans, especially in the determination of the sex of whole skeletons, or isolated parts, the process of identification becomes progressively

Access this article online Quick Response Code

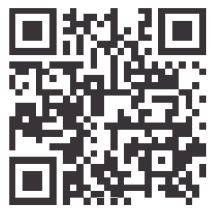
complex. ${ }^{11}$ Determination of gender and estimation of age are the two most important attributes of biological identity of an individual. Both the morphological and morphometrical traits of human skeletal elements have been widely used in establishingsuch as an identity of a person. ${ }^{15}$

Of all the long bones, the clavicle is the only one placed horizontally in the body and it possesses many gender and age specific non-metric traits. ${ }^{15}$ The rhomboid fossa of clavicle is one of these morphologic traits which have been studied by various workers as an estimator of sexand age. ${ }^{11 .}$ ${ }^{15,7,6}$ Sexing methods are suitable only for the population group from which they were derived and the reliability of a method decreases when it is applied to another unrelated population group. ${ }^{11,4}$

Previous studies have evaluated the relationship between the presence of clavicular rhomboid fossa, and sex in skeletons of various human populations worldwide, and found significant results related to incidence of the rhomboid fossa, being higher in males than females. ${ }^{11,10,5}$

Jit and Kaur (1986) did not find statistically significant differences between sex in relation to incidence of the rhomboid fossa in Indian individuals. It was also noted that 
in various zones of India the length of the clavicle was different ${ }^{1}$. The clavicles of the French and the northwest Indians were more curved in their medial two-thirds than the clavicles of the American Negroes, American whites and the English. ${ }^{1}$

India having human groups carrying a diversity of genes and cultural traits, has almost all the primary ethnic strains Proto-Australoid (skin colour-dark brown), M editerranean (skin colour-light brown), M ongoloid (skin colour-yellow), Negrito (skin colour-black) and a number of composite strains. ${ }^{3}$

The South India is inhabited mainly by dravidian racial group and study on rhomboid fossa in South Indian population is very limited. Hence the present study was conducted to scrutinize the reliability of rhomboid fossa of the clavicle as an indicator of gender of isolated clavicle specimen from individual of south Indian population.

\section{M aterials and M ethods}

The present study has been conducted at department of Anatomy, Yenepoya Medical College, Mangalore, Karnataka, South India. These clavicles were collected from grave yards of North Karnataka region. The people of this group belong mainly to Lingayath community of Dravidian ethnic group of South India. The burial of cadavers is practised in these people, so we could obtain dry clavicle specimens. We had collected 315 numbers of clavicles. The bones were sorted out and only good clavicles were selected. The clavicles which are mutilated and fractured, excluded from the study. Totally we used 246 clavicles for our study. The study of wet specimens is tedious process because of difficulty in procuring such large number of specimens, due to shortage of supply of cadavers.

The Clavicles were classified into male and female by its gross osteological features (Fig.1). The mid shaft circumference is measured using scale and measuring tape. Morphological feature of the rhomboid fossa is recorded by physical observation of each clavicle.

All the above parameters collected are compared between sexes by statistical analysis to determine their significance.
The statistical analysis was done by Fischer's exact probability test and student unpaired' $t$ ' test.

The comparison of morphological features of rhomboid fossa between sexes is done using Fischer's exact probability test. Fisher's exact test is a statistical significance test used for small sample sizes. It is one of a number of tests used to analyse contingency tables, which display the interaction of two or more variables. It is called exact because it calculates statistical significance exactly, rather than by using an approximation. The comparison of mid shaft circumference is done by unpaired student ' $\mathrm{t}$ ' test.

Necessary ethical clearance (YUEC 50/6.2.13 dated 05-022013) was taken from the institutional ethical committee of Yenepoya M edical College.

\section{Results}

In the present study, initially we catego rised these clavicles into male and female types (Table1). The medial end showed different outlines like triangular, oval or quadrilateral shapes. In this present study the female clavicle is shorter, thinner, less curved and male clavicles were longer, curvy and robust (Fig.1).

The inferior surface of clavicle near its sternal end showed the rhomboid fossa. It has oval outline and there are three distinct types viz. flat, elevated and depressed. In some of the clavicles, the rhomboid fossae were appeared smooth (Fig.1) which is classified as smooth type of rhomboid fossa.

The different morphological types of rhomboid fossa, their presence in sexes for right and left sides were observed (Table.1). The male clavicles showed depressed type of rhomboid fossa on right and left sides $(60.76 \%$ and $27.85 \%$ ) respectively compared to females $(6.81 \%$ each on both sides). the percentage of elevated rhomboid fossa was more in males on both sides compared to females. In contrast smooth and flat types of rhomboid fossa were found more in females (flat type rhomboid fossa left side $20.45 \%$ and right side $31.81 \%$; smooth type rhomboid fossa left side $18.18 \%$ and right side $13.63 \%$ ). 
On overall observation depressed and elevated types (88.61\% and $10.13 \%$ ) of rhomboid fossa is more in males and smooth and flat types ( $31.8 \%$ and $52.27 \%$ ) are seen mainly in female clavicles. This is shown in table 1 . The Fischer's Exact Probability test for both right and left sides between the sexes are highly significant $(p \varangle 0.001)$. This shows that there is definite sexual dimorphism in the incidence of rhomboid fossa.

Table 1 : Types of Rhomboid Fossa of Clavicle among male and female.

\begin{tabular}{|c|c|c|c|c|c|c|c|c|}
\hline \multirow[t]{3}{*}{ Gender } & \multicolumn{8}{|c|}{ Type of Rhomboid Fossa of Clavicle } \\
\hline & \multicolumn{2}{|c|}{ Smooth } & \multicolumn{2}{|c|}{ Flat } & \multicolumn{2}{|c|}{ Depressed } & \multicolumn{2}{|c|}{ Elevated } \\
\hline & Left & Right & Left & Right & Left & Right & Left & Right \\
\hline $\begin{array}{l}\text { M ale } \\
(n=158) \\
L=50, \\
R=108\end{array}$ & 00 & 00 & $02(1.27 \%)$ & 00 & $44(27.85 \%)$ & $96(60.76 \%)$ & $04(2.53 \%)$ & $12(7.59 \%)$ \\
\hline $\begin{array}{l}\text { Female } \\
(n=88) \\
L=40, \\
R=48\end{array}$ & $16(18.18 \%)$ & $12(13.63 \%)$ & $18(20.45 \%)$ & $28(31.81 \%)$ & $06(6.81 \%)$ & $06(6.81 \%)$ & 00 & $02(2.27 \%)$ \\
\hline Total & $\begin{array}{r}\text { Male } \\
\text { Female }=\end{array}$ & $\begin{array}{l}=0 \% \\
28(31.8 \%)\end{array}$ & $\begin{aligned} \text { Male } & =2 \\
\text { Female } & =4\end{aligned}$ & $\begin{array}{l}(1.27 \%) \\
6(52.27 \%)\end{array}$ & $\begin{array}{c}\text { Male }=14 \\
\text { Female }=\end{array}$ & $\begin{array}{l}0(88.61 \%) \\
2(13.64 \%)\end{array}$ & $\begin{array}{l}\text { Male }=1 \\
\text { Female }\end{array}$ & $\begin{array}{l}(10.13 \%) \\
2(2.27 \%)\end{array}$ \\
\hline
\end{tabular}

Table 2 : M id Shaft Circumference of male and female Clavicles

\begin{tabular}{|l|l|c|c|c|c|c|c|c|c|c|c|c|}
\hline Male Clavicles & Mid Shaft Circumference & $4.0 \mathrm{~cm}$ & $4.1 \mathrm{~cm}$ & $4.2 \mathrm{~cm}$ & $4.3 \mathrm{~cm}$ & $4.4 \mathrm{~cm}$ & $4.4 \mathrm{~cm}$ & $4.6 \mathrm{~cm}$ & $4.0 \mathrm{~cm}$ & $4.1 \mathrm{~cm}$ & $4.2 \mathrm{~cm}$ & $4.3 \mathrm{~cm}$ \\
\hline & No. of males $(\mathrm{n}=158)$ & 15 & 18 & 18 & 15 & 11 & 08 & 06 & 11 & 21 & 19 & 16 \\
\hline Female Clavicles & Mid Shaft Circumference & $2.5 \mathrm{~cm}$ & $2.6 \mathrm{~cm}$ & $2.7 \mathrm{~cm}$ & $2.8 \mathrm{~cm}$ & $2.9 \mathrm{~cm}$ & $3.0 \mathrm{~cm}$ & $3.1 \mathrm{~cm}$ & $3.2 \mathrm{~cm}$ & $3.3 \mathrm{~cm}$ & $3.4 \mathrm{~cm}$ & $3.5 \mathrm{~cm}$ \\
\hline & No. of females $(\mathrm{n}=88)$ & 2 & 4 & 8 & 4 & 8 & 10 & 10 & 16 & 8 & 12 & 6 \\
\hline
\end{tabular}

M ale Clavicles: Average $=4.3 \mathrm{cms}$; Female Clavicles: Average $=3.0 \mathrm{cms}$

Fig. 1 : Different types of Rhomboid Fossa of Clavicles.( Photo's. 1., 2., 3., 4. \& 5.)
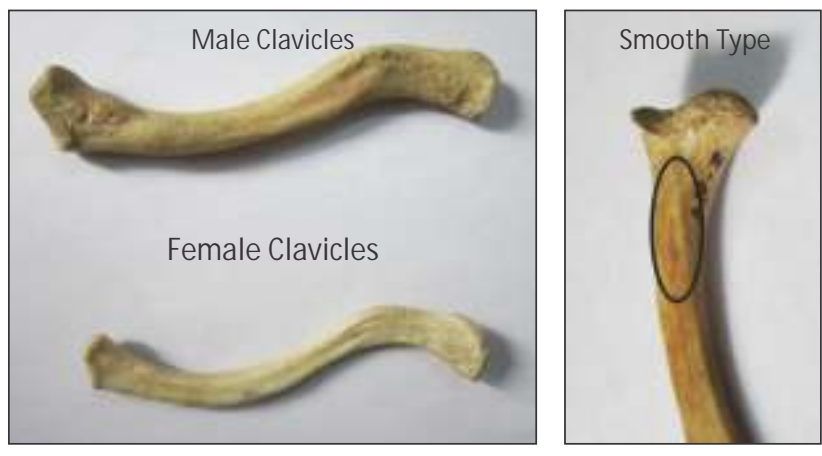

\section{Discussion}

Biological profiling of any unclaimed, mutilated or dismembered cadaver is the primary task of any forensic expert or anthropologist. Determination of gender and age are the most important attributes of biological identity of an individual. ${ }^{15}$
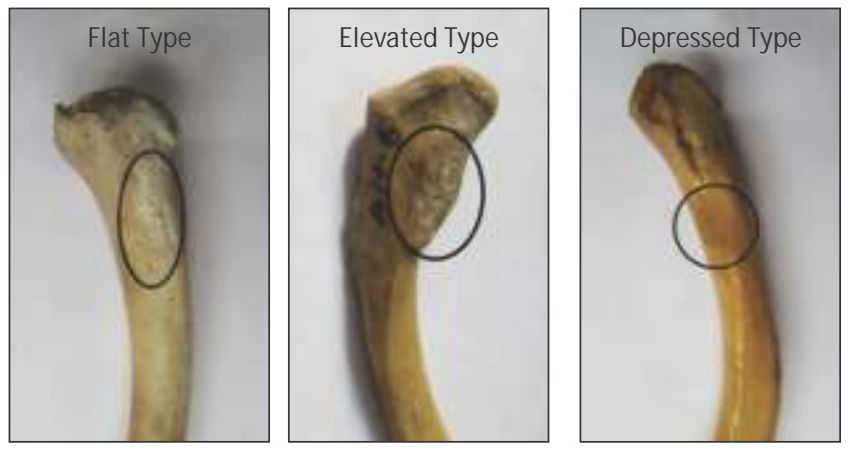

The earlier studies on rhomboid fossa of clavicle in different geographical and ethnic groups of population like North Indians, Brazilians, and Nepalese showed anthropological and forensic significance. ${ }^{15,11,7,6}$ Rani et al showed various patterns of rhomboid fossae in North Indians. ${ }^{12}$ 
The males had greater tendency of having rhomboid fossa than females which will help in sex determination of clavicle samples. ${ }^{15}$ Younger individuals showed prominent rhomboid fossae than older individuals and the larger fossa were in males aged 20-30 years ${ }^{13}$. The excavated type of rhomboid fossa is a relatively neglected anatomical structure that can potentially cause diagnostic problems. Its unilateral occurrence may be confused by the physicians as avascular necrosis, osteomyelitis or even a tumour which is visualised in radiographs of shoulder girdle or chest. ${ }^{9}$ Rhomboid fossa was absent in most of the female clavicles in Brazilian population. ${ }^{11}$ Very few female clavicles and $1 / 3^{\text {rd }}$ of male clavicles showed bilateral incidence of rhomboid fossae. ${ }^{11}$

Jit and Kaur in their study showed no significant sexual dimorphism of clavicular rhomboid fossa with $59 \%$ in males and $54 \%$ in females. ${ }^{7}$ The study conducted by Shobha showed clavicular parameters like length, midshaft circumference, robustness index, weight, volume, morphometry of rhomboid fossa are statistically highly significant predictors of sex. The male clavicles more commonly exhibited rhomboid fossa. The mid shaft circumference of left clavicles showed sexual difference. ${ }^{14}$

The female clavicle is shorter, thinner, less curved and smoother, and its acromial end is carried lower than the sternal end in comparison with the male. In males the acromial end is in level with, or slightly higher than the sternal end. ${ }^{6}$ Mid-clavicular circumference is the most reliable single indicator of sex: a combination of this measurement with weight and length yields better results. ${ }^{6}$

In our present study, there is relative difference in the incidence of rhomboid fossa between male and female

\section{References}

1. Kaur H, Harjeet, SD, Jit I. Length And Curves Of The Clavicle In Northwest Indians. J Anat Soc India. 2002;51(2):199-9.

2. Abe K. An effort at racial classification of the people in South India and Sri Lanka. Principal component analysis on 23 ethnic groups. Juntendo Univ Bull Lett Sci. 1985;28: 12-18.

3. Williams PL. Gray's Anatomy. 38th edition, ELSEVER Churchill Livingstone. 1995.

4. Calcagno JM . On the applicability of sexing human skeletal material by discriminant function analysis. J Hum Evol. 1981;10:189-98. clavicles (Table 1). The incidences of rhomboid fossae of depressed and elevated types were more in males than in females. The Fischer's Exact Probability test for both right and left sides between the sexes are highly significant. This shows that there is definite degree of sexual dimorphism in the incidence of rhomboid fossa. The average mid shaft circumference is more in males compared to females (Table 2). The ' $p$ ' value is less than 0.001 which shows that it is highly significant on applying unpaired't' test. The findings of the present study also supported the findings of various authors that, there is relative degree of sexual dimorphism in the mid shaft circumference of male and female clavicles. ${ }^{11,15,7,6,8}$

The information gathered from different sources will contribute to the effective determination of sex of the bone or bone fragments in forensic cases along with this type of osteological studies. ${ }^{15,6,11,14,7,8,10}$ In such situations, the presence of rhomboid fossa would indicate whether the clavicle is derived from a male or a female. ${ }^{15,6,10,8,14}$

\section{Conclusion}

The present study revealed that, depressed and elevated types of rhomboid fossae are more common in male clavicles and smooth and flat types of rhomboid fossae in female clavicles. This study elucidated significant degree of sexual dimorphism of rhomboid fossa of clavicle and also in mid shaft circumference. This observation will lighten to further studies on molecular analysis related to sexual dimorphism and type of clavicle in recent specimens. The results of molecular studies can be correlated with type and the sex of clavicle which can be used as a qualitative criterion in differentiation of sex of clavicles from skeletal remains of cadavers in the population of Dharwad and Bijapur area of North Karnataka of South India.

5. Cave AJE. The nature and morphology of costoclavicular ligament. J Anat. 1961;95:170-79.

6. Haque M K, M ansur ID, Krishnamurthy A, Karki R, Sharma K, Shakya R. M orphometric analysis of clavicle in nepalese population. Kathmandu Univ M edJ (KUMJ). 2011; 9(35):193-7.

7. Jit I, Kaur H. Rhomboid fossa in the clavicles of North Indians. Am J Phys Anthropol. 1986;70: 97-3.

8. McCormick WF, Stewart JH, Greene H. Sexing of human clavicles using length and circumference measurements. Am J Forensic Med Pathol. 1991;12(2): 175-81. 
9. Paraskevas G, Natsis K, Spanidou S. Excavated Type of Rhomboid Fossa of the Clavicle - A Radiological Study. Folia Morphol(Warsz ).2009; 68(3):163-6.

10. Parsons FG. On the proportions and charecteristics of the modern English clavicle. J Anat. 1916;51:71-93.

11. Prado FB, De Mello Santos LS, Caria PH, Kawaguchi JT, Preza Ad, Daruge JE, da Silva RF, Daruge E. Incidence of clavicular rhomboid fossa (impression for costoclavicular ligament) in the Brazilian population: forensic application.J Forensic Odontostomatol. 2009;27(1):12-16.

12. Rani A, Chopra J, Mishra SR, Srivastava AK, Sharma PK, Diwan R (2011) A Study of Morpholgical Features of Attachment Area of Costoclavicular Ligament on Clavicle and First Rib in Indians and its Clinical Relevance. Biomedical Research. 2011;22(3):349-54.

13. Rogers NL, Flournoy LE, M cCormick WF. The Rhomboid Fossa of the Clavicle as a Sexand Age Estimator.J Forensic Sci. 2000;45(1):61-7.

14. Shobha. Determination of sex of adult human clavicle by morphometric parameters. [dissertation]. Bangalore, Karnataka, India. Rajiv Gandhi University of Health Sciences. 2010.

15. Singh M, Singh D (2009) Rhomboid Fossa of Clavicle: Is It A Reliable Estimator of Gender and Age of Northwest Indian Subjects of Chandigarh Zone. Journal of Punjab Academy of Forensic Medicine and Toxicology, 9(1): 58-65. 